\title{
Improvement of the "Perturb and Observe" MPPT Algorithm in a Photovoltaic System under Rapidly Changing Climatic Conditions
}

\author{
Ali Chermitti \\ URMER Research unit, \\ Tlemcen University, \\ B.P. 119, Tlemcen,Algeria
}

\author{
Omar Boukli-Hacene \\ Tlemcen University, \\ FT/GEE/Laboratory of automatic \\ B.P. 230, Chetouane, Algeria
}

\author{
Bencherif Mohamed \\ URMER Research unit, \\ Tlemcen University, \\ B.P. 119, Tlemcen, Algeria
}

\begin{abstract}
The power delivered by a photovoltaic power system depends strongly on the level of sunlight, the cell temperature and the nature of the load supplied, Itis therefore highly unpredictable. This paper presents the improvement of the MPPT algorithm Perturb and Observe $(\mathrm{P} \& \mathrm{O})$ under rapidly changing climatic conditions. The results of the simulation in Simulink confirm the efficiency of the proposed method.
\end{abstract}

\section{General Terms}

Photovoltaic systems,Maximum Power Point Tracking,Optimization system, Rapidly changing climatic conditions.

\section{Keywords}

Photovoltaic system, Perturb and Observe MPPT algorithm, Modeling, Improvement, Simulation, Rapidly changing climatic conditions.

\section{INTRODUCTION}

The renewable energy sources like wind, solar, geothermal and biomass represent an alternative to traditional methods of producing electrical energy. The latters reject harmful combustion wastes and seriously affect the quality of life on earth. Solar energy can be converted directly into electricity using photovoltaic panels (PV) through the photovoltaic effect. However, the conversion efficiency is low and the cost of power generated is relatively high.

The power characteristic of the PV generator (PVG) is nonlinear and has a particular point for which the power generated by the PVG is maximal. This is usually noted MPP (Maximum Power Point). The MPPT (Maximum Power Point Tracker) is an electronic device inserted between the PVG and its load. It aims to maintain the operating point of the system as close to the MPP. There are several MPPT algorithms in the literature, the most widely used algorithm is the "Perturb and Observe" (P\&O).

The purpose of this paper is the study, analysis and improvement of $\mathrm{P} \& \mathrm{O}$ MPPT algorithm under a rapid change in the radiation level.

This paper is organized as follows: the PV generator is described in Part II. The matching stage between PVG and a load is presented in Part III. The MPPT converter and the P\&O MPPT algorithm are described in Part IV. The improvement of $\mathrm{P} \& \mathrm{O}$ algorithm in the case of a rapid change of the lighting level is detailed in Part V. The simulation results are illustrated in Section VI, followed by a conclusion in the last part.

\section{THE PHOTOVOLTAIC GENERATOR}

The PV cell is the basic element of a PV system. A set of cells electrically connected together form a PV module, several modules form a panel and several panels form a PV array. We will use the term PV generator (PVG) to designate a module or a PV panel.

\subsection{Modeling of the PVG}

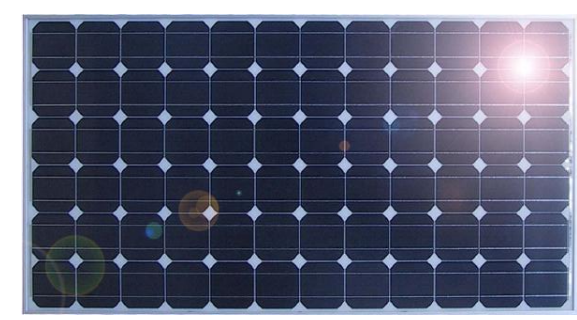

Fig 1: PV module (PVG)

One realizes a PV panel by connecting several PV cells properly between them. The mathematical model of the PVG is given by $[1,2,3,4,5,6,7,20]$ :

$I^{P}=I_{s c}^{P}\left[1-\exp \left(\frac{V^{P}-V_{o c}^{P}+I^{P} R_{s}^{P}}{N_{s} V_{t h}^{C}}\right)\right]$

where the subscript " $\mathrm{P}$ " indicates the parameters of the panel and the index " $\mathrm{C}$ ", the parameters of the PV cell $[1,5,6,12]$

\subsection{Current/Voltage (I/V) Characteristic of the PVG}

Figure 2 illustrates theI/V characteristics of a PVG and a resistive load $\mathrm{R}$. The resistance characteristic is a line of slope $1 / \mathrm{R}$. The operating point $(\mathrm{OP})$ is located at the intersection of the two curves. In the $\mathrm{AB}$ region of the curve the PVG behaves as a current generator and in the $\mathrm{CD}$ region it behaves like a voltage source. In the intermediate zone $\mathrm{BC}$, the characteristic of the PVG is nonlinear, it is in this area that we find the MPP (Maximum Power Point) for which the PVG 
provide its full power for certain atmospheric conditions. The resistance value corresponding to this point is denoted $R_{\text {opt }}$ [5].

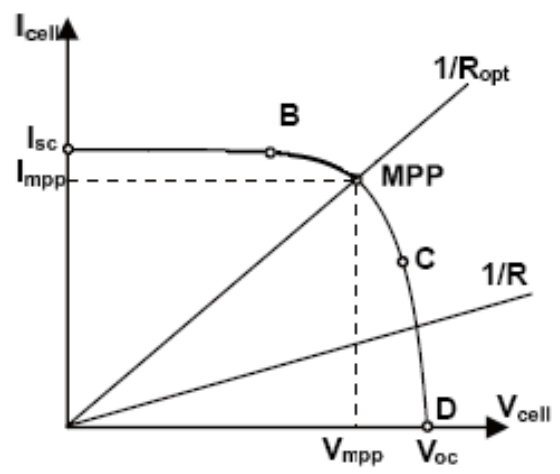

Fig 2: I/V Characteristics of the GPV and a resistive load

In practice, in the case of a direct coupling of a PVG and a load, the OP rarely coincides with the MPP. For this reason, a matching stage, to transfer maximum power from the source to the load is necessary.

\section{MATCHING STAGE BETWEEN PVG AND A LOAD}

\section{A}

The commonly used adapter in PV systems is a DC/DC power converter. It ensures, through a control action, the transfer of the maximum of electrical power to the load. The structure of the converter is determined according to the load to be supplied. In this article we focus on the step-down DC/DC converter (Buck converter).

\subsection{DC/DC Buckconverter}

A Buck converter (figure 3) is a switching power supply which converts a DC voltage into another DC voltage of lower value. This type of converter is used as an adapter between the source and the load, when the OP is to the left of the MPP in direct coupling [1,8,9,10,11].

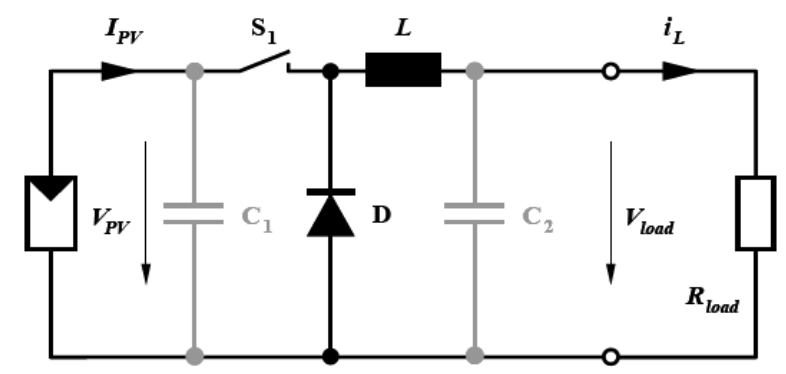

Fig 3: Electrical circuit of a Buck converter

In this case, the voltage across the load in continuous conduction mode is given by:

$$
V_{\text {load }}=D V_{p v}
$$

where $\mathrm{D}=\mathrm{t}_{\mathrm{on}} / \mathrm{T}$ is the duty cycle $(0<\mathrm{D}<1)$

$$
\mathrm{T}=\mathrm{t}_{\mathrm{on}}+\mathrm{t}_{\mathrm{off}} \text { is the switching period }
$$

\section{THE MPPT CONVERTER}

The power delivered by a PVG depends greatly on the level of sunshine, temperature and also the nature of the load supplied. It is therefore highly unpredictable. The power characteristic (figure 4) has a maximum corresponding to the MPP.

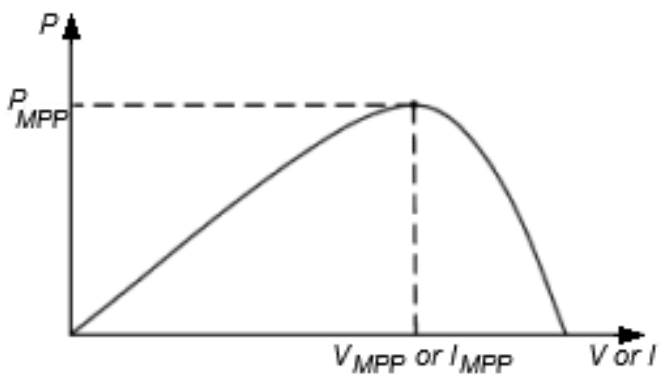

Fig 4: Power Characteristic of the GPV

The MPP position, depending on the various factors mentioned above, is never constant over time. The role of the DC/DC converter is to maintain the OP as close to the MPP for any operating conditions. An appropriate command will achieve this goal. Then we obtain a MPPT converter (Maximum Power Point Tracker).The MPPT converter is a power conversion system with a control algorithm for extracting the maximum power from the PVG[1,8,9,10,11]. It regulates the input voltage $\mathrm{V}_{\mathrm{pv}}$. The reference voltage is then imposed by the control algorithm.

\subsection{Principle of research of the MPP}

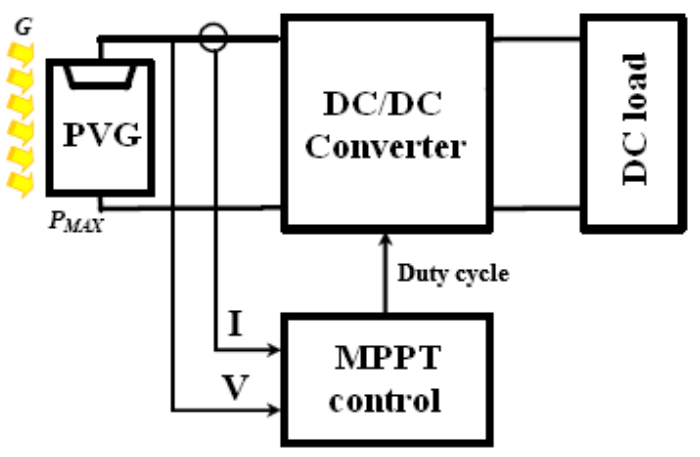

Fig 5: Principle diagram of the MPPT converter

Figure 5 shows the schematic diagram of a conventional MPPT converter. The MPPT control varies the duty cycle D using pulse width modulation (PWM) signal. The MPPT algorithm is based on the variation of duty ratio of DC / DC converter according to the evolution of its input parameters (I and $\mathrm{V}$ and therefore the power of the PVG) to be placed on the MPP [13].

\subsection{The Perturb and Observe MPPT algorithm (P\&O)}

The P\&O method is generally the most used because of its simplicity and ease of implementation $[2,4,14,15,16]$. As its name indicates, this method works by perturbing the system and observing the impact on output power of PVG. In figure 6 , one sees that if the operating voltage is perturbed in a given 
direction and that the power increases $(\mathrm{dP} / \mathrm{dV}>0)$, then it is clear that the perturbation has moved the operating point toward the MPP. The $\mathrm{P} \& \mathrm{O}$ algorithm will continue to perturb the tension in the same direction. By cons, if the power drops $(\mathrm{dP} / \mathrm{dV}<0)$ then the perturbation has moved theoperating point away from the MPP. The algorithm will reverse the direction of the next perturbation. This algorithm is summarized in Table $1[4,16]$ and the flowchart in figure $7[2,12]$.

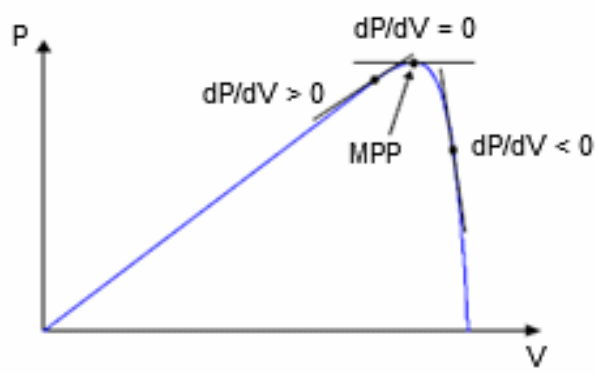

Fig 6: Sign of dP/dV at different positions of the power characteristic curve

The process is periodically repeated until the MPP is reached. The system oscillates around the MPP, which causes power loss. The oscillation can be minimized by decreasing the size of the perturbation. However, a too small perturbation slows considerably tracking the MPP. Then there is a compromise between accuracy and speed [16].

TABLE I.

\begin{tabular}{|c|c|c|}
\hline Perturbation & Change in Power & Next perturbation \\
\hline positive & positive & positive \\
\hline positive & negative & negative \\
\hline negative & positive & negative \\
\hline negative & negative & positive \\
\hline
\end{tabular}

One drawback of the $\mathrm{P} \& \mathrm{O}$ algorithm is that it can fail during a rapidly changing climatic conditions such as illustrated in figure $8[2,5,16,17]$. Starting from point $A$, if the weather conditions remain constant, a perturbation $\Delta \mathrm{V}$ in the voltage will move the OP to point $\mathrm{B}$, and the direction of the next perturbation is reversed due to the decrease in power.By cons, if the illumination increases and move the power curve $\mathrm{P}_{1}$ to $\mathrm{P}_{2}$ on a MPPT cycle, the operating point will be moved from A to $C$. This represents an increase of power, the algorithm interprets this as the result of its own action and the direction of the perturbation remains the same.Therefore, the operating point moves away from the MPP and continue to diverge if the illumination increases (or decreases) gradually [12].

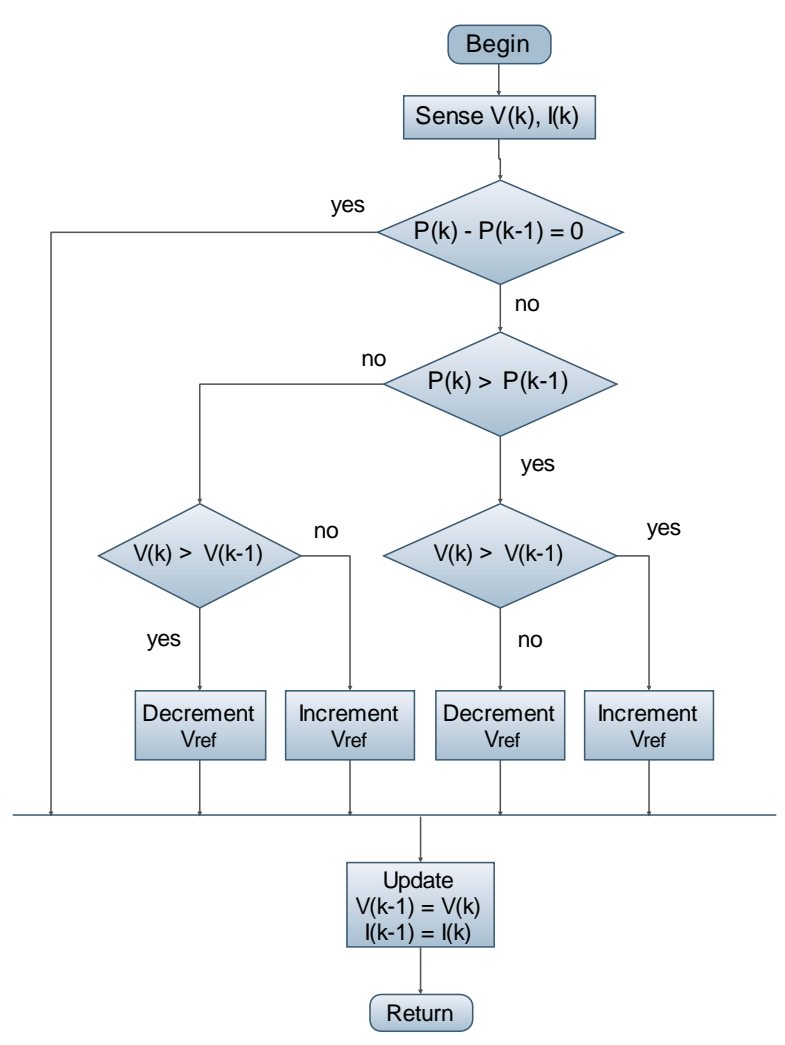

Fig 7: Chart of the P\&O algorithm

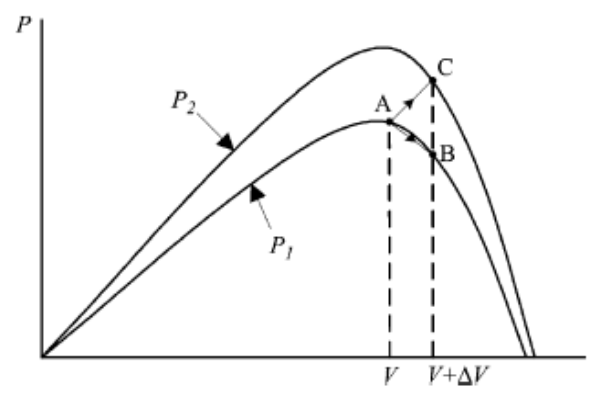

Fig 8: Divergence of the $\mathrm{P \& O}$ method during a rapidly changing irradiance level

\section{IMPROVEMENT OF THE P\&O ALGORITHM}

As seen in previous section, the $\mathrm{P} \& \mathrm{O}$ algorithm can fail during rapidly changing climatic conditions. The solution proposed by some authors $[18,19]$ to this problem is to introduce a new condition in the MPPT algorithm. It has been shown that the rapid increase of the illumination is characterized by the increase in power twice in the last two cycles of the algorithm or by the sense of perturbation which remains the same during two cycles. A solution to the problem of misinterpretation would be to reverse the direction of perturbation when this event occurs. For this, the algorithm must take into account the variations of power $\Delta \mathrm{P}$ and voltage $\Delta \mathrm{V}$ at times (k) and (k-1).The improved algorithm then uses four variables, which gives 16 possible cases as shown in Tables II and III (G represents the irradiance). The 
contribution of improvement is noted NCC for New Control Condition.

TABLE II.

\begin{tabular}{|c|c|c|c||c||c|}
\hline$\Delta \mathbf{V}(\mathbf{k}-1)$ & $\Delta \mathbf{P}(\mathbf{k}-1)$ & $\Delta \mathbf{V}(\mathbf{k})$ & $\boldsymbol{\Delta P}(\mathbf{k})$ & Case & $\Delta \mathbf{V}(\mathbf{k}+\mathbf{1})$ \\
\hline \hline- & - & - & - & 1 & + \\
\hline- & - & - & + & 2 & + \\
\hline- & - & + & - & 3 & - \\
\hline- & - & + & + & 4 & + \\
\hline- & + & - & - & 5 & + \\
\hline- & + & - & + & 6 & + \\
\hline- & + & + & - & 7 & - \\
\hline- & + & + & + & 8 & - \\
\hline+ & - & - & - & 9 & + \\
\hline+ & - & - & + & 10 & - \\
\hline+ & - & + & - & 11 & - \\
\hline+ & - & + & + & 12 & - \\
\hline+ & + & - & - & 13 & + \\
\hline+ & + & - & + & 14 & + \\
\hline+ & + & + & - & 15 & - \\
\hline+ & + & + & + & 16 & - \\
\hline
\end{tabular}

TABLE III.

\begin{tabular}{|c||l|}
\hline Case & \multicolumn{1}{|c|}{ Description } \\
\hline 1 & invalid, $\mathrm{V}<\mathrm{V}_{\mathrm{MPP}}$ \\
\hline 2 & invalid, $(\mathrm{G} \nearrow), \mathrm{NCC}$ \\
\hline 3 & $\mathrm{G} \searrow$ \\
\hline 4 & $\mathrm{~V}<\mathrm{V}_{\mathrm{MPP}}$ \\
\hline 5 & $\mathrm{~V} \simeq \mathrm{V}_{\mathrm{MPP}}$ ou $\mathrm{G} \searrow$ \\
\hline 6 & $\mathrm{~V}>\mathrm{V}_{\mathrm{MPP}}$ ou $\mathrm{G} \searrow, \mathrm{NCC}$ \\
\hline 7 & $\mathrm{~V}>\mathrm{V}_{\mathrm{MPP}}$ \\
\hline 8 & $\mathrm{G} \nearrow, \mathrm{NCC}$ \\
\hline 9 & $\mathrm{G} \searrow$ \\
\hline 10 & $\mathrm{~V}>\mathrm{V}_{\mathrm{MPP}}$ \\
\hline 11 & invalid, $\mathrm{V}>\mathrm{V}_{\mathrm{MPP}}$ \\
\hline 12 & invalid $(\mathrm{G} \nearrow), \mathrm{NCC}$ \\
\hline 13 & $\mathrm{~V}<\mathrm{V}_{\mathrm{MPP}}$ \\
\hline 14 & $\mathrm{G} \nearrow, \mathrm{NCC}$ \\
\hline 15 & $\mathrm{~V} \simeq \mathrm{V}_{\mathrm{MPP}}$ ou $\mathrm{G} \searrow$ \\
\hline 16 & $\mathrm{~V}<\mathrm{V}_{\mathrm{MPP}}$ ou $\mathrm{G} \nearrow, \mathrm{NCC}$ \\
\hline
\end{tabular}

If the increase in power is caused by the perturbation and not by increase of the illumination, the improved $\mathrm{P} \& \mathrm{O}$ algorithm causes decrease in power for one cycle (wrong direction of perturbation), but takes again in the right direction in the next cycle.

However, this improvement has a drawback as it can be seen in the simulation results. Indeed, when the variation of the load and also when the radiation level remains stable, the improved $\mathrm{P} \& \mathrm{O}$ algorithm takes longer than the classical algorithm to reach the MPP. This is due to the damping of the response resulting from the NCC added. To overcome this problem, the solution we propose is to use a variable perturbation step. One then uses two values according to the amplitude of the variation of the power at the instant (k). If the variation of the power is below a certain threshold, one will use a minimum perturbation step. Otherwise, a maximum perturbation step is used.

\section{SIMULATION RESULTS}

To perform the simulation of $\mathrm{P} \& \mathrm{O}$ MPPT algorithms, the library of components for a standalone PV system
(Photovoltaic Systems Toolbox) developed under Matlab/Simulink is used [20].

TABLE IV.

\begin{tabular}{|c|c|}
\hline Number of cells & 36 serial \\
\hline Open circuit voltage $\left(\mathbf{V}_{\mathbf{~ o c}}\right)$ & $21.6 \mathrm{~V}$ \\
\hline Short-circuit current $\left(\mathbf{I}_{\mathbf{s c}}\right)$ & $5.16 \mathrm{~A}$ \\
\hline MPP voltage $\left(\mathbf{V}_{\mathbf{M P P}}\right)$ & $17.3 \mathrm{~V}$ \\
\hline MPP Current $\left(\mathbf{I}_{\mathbf{M P P}}\right)$ & $4.63 \mathrm{~A}$ \\
\hline Maximum power $\left(\mathbf{P}_{\mathbf{M P P}}\right)$ & $80 \mathrm{~W}$ \\
\hline
\end{tabular}

The PVG chosen for the simulation is the SH- 80 from Sharp with a maximum power of $80 \mathrm{~W}$. Its parameters are given in Table 4. Regarding the parameters of the buck converter, their values are: $\mathrm{L}=120 \mu \mathrm{H}, \mathrm{C}_{1}=10 \mu \mathrm{F}, \mathrm{C}_{2}=55 \mu \mathrm{F}$, the load is a lead acid battery with $12 \mathrm{~V}$ nominal voltage. The switching frequency of the buck converter is $100 \mathrm{kHz}$ and the MPPT frequency is $1 \mathrm{kHz}$.

\subsection{P\&O algorithms performance under rapidly changing illumination}

The simulation results of the classical $\mathrm{P} \& \mathrm{O}$ algorithm under rapidly changing radiation level are shown in figures 9 and 10 . The perturbation step of the duty ratio is $1 \%$.

The simulation results show that the rapid increase of illuminationleads the classical $\mathrm{P} \& \mathrm{O}$ algorithm to a misinterpretation. Indeed, as the illumination increases, the OP moves away from the MPP. Seen that the MPPT is fast enough, it happens at a certain moment to resume in the right direction. The algorithm then reaches the MPP, unfortunately it continue to perturb the system in the same direction, which moves away once again the OP from the MPP. This phenomenon occurs as long as the radiation level increases (or decreases) and does not stop until it becomes stable (which is improbable in practice). The power loss caused by this misinterpretation is not very large, because the MPPT is fast enough. Nevertheless the algorithm can be improved to avoid this phenomenon.

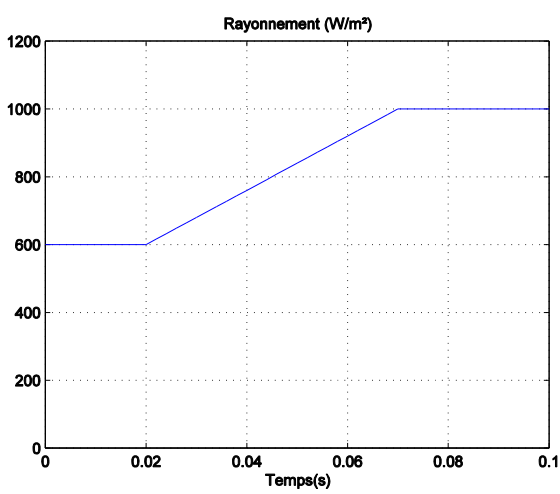

Fig 9 : Rapidly changing radiation level 

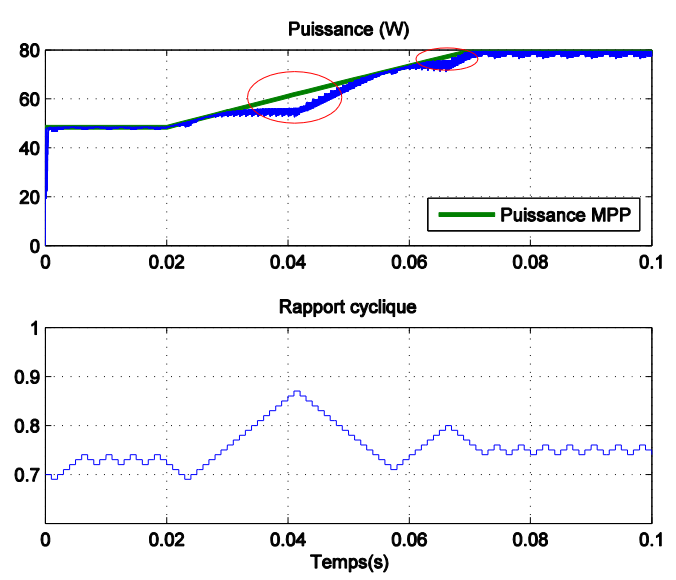

Fig 10: Simulation result of the classical $P \& O$ algorithm during a rapidly changing radiation level (GPV power and duty cycle)
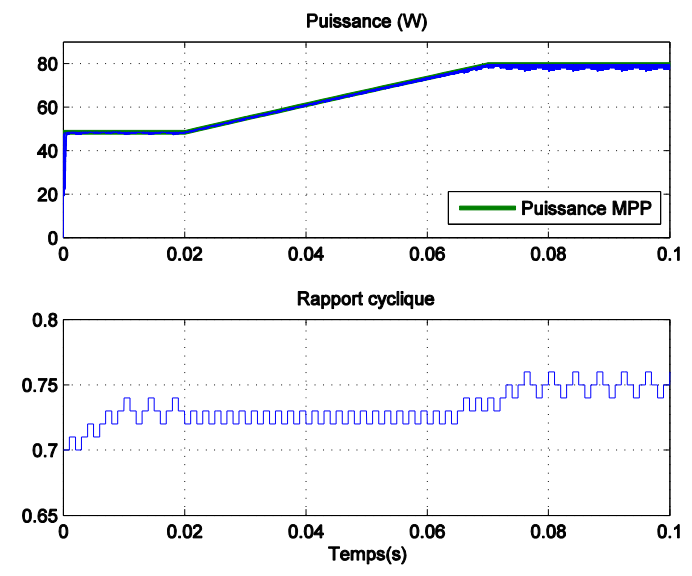

Fig 11: Simulation result of the improved $\mathrm{P} \& O$ algorithm during a rapidly changing radiation level (GPV power and duty cycle)

Figure 11 shows the simulation result of the improved $\mathrm{P} \& \mathrm{O}$ algorithm for the same operating conditions. It is noted that when the increase in power is the result of increasing of the illumination, reversing the direction of the perturbation produced by the improved $\mathrm{P} \& \mathrm{O}$ algorithm causes the increase of power. Therefore, the system oscillates around the last OP until the irradiance becomes stable. The improved algorithm gives better results than the classical $\mathrm{P} \& \mathrm{O}$ algorithm.

\subsection{Performance duringload variation}

To test the behavior of the system during a load variation, a resistive load is added at $t=0.02 \mathrm{~s}$. The simulation results of the classical algorithm and the improved algorithm are given in figures 12 and 13 respectively.
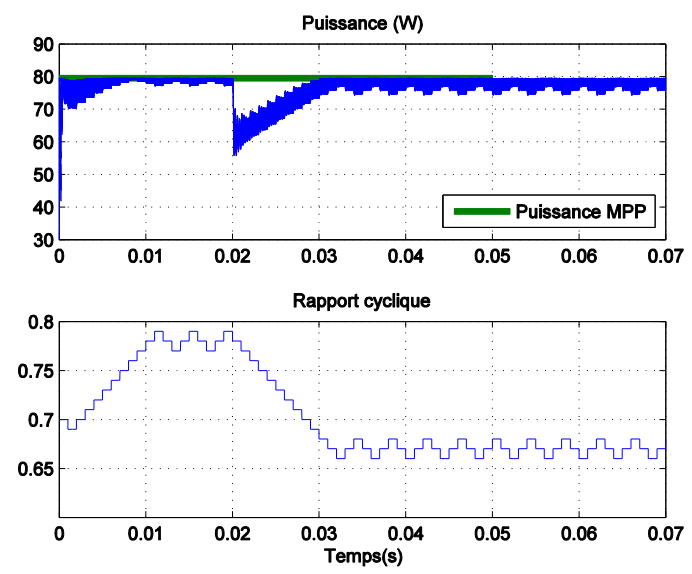

Fig 12 : Simulation result of the classical $P \& O$ algorithm during load variation (GPV power and duty cycle)
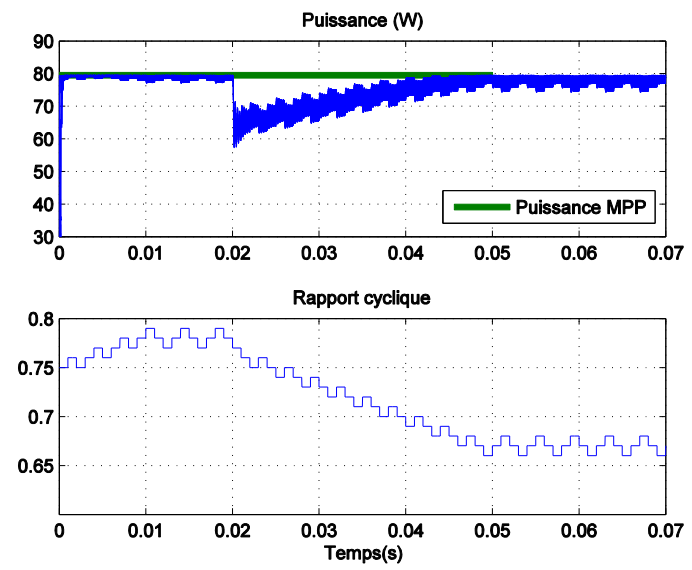

Fig 13: Simulation result of the improved P\&O algorithm during load variation (GPV power and duty cycle)
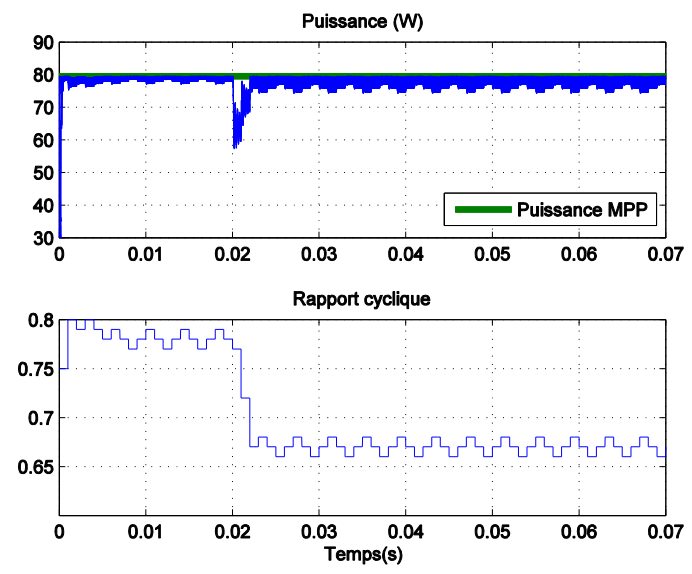

Fig 14: Simulation result of the improved P\&O algorithm with variable perturbation step during load variation (GPV power and duty cycle)

It is seen that the improved algorithm takes more time than the classical algorithm to reach the MPP. The solution we propose is to use a variable perturbation step. For example, if the variation of the power is below a certain threshold (chosen empirically), we use a perturbation step of $1 \%$. Otherwise, a 
perturbation step of $5 \%$ is chosen. According to the simulation results (Figure 14), it is clear that the improved $\mathrm{P} \& \mathrm{O}$ algorithm with variable perturbation step gives better results. Indeed, the tracking of MPP is instantaneous in this case.

\section{CONCLUSION}

In this article, we presented the improvement of the $\mathrm{P} \& \mathrm{O}$ MPPT algorithm in a standalone photovoltaic system in the case of rapidly changing climatic conditions. The component library "Photovoltaic Systems Toolbox" was used to perform the simulation. The results of the simulation using a SH-80 PV module from Sharp with a maximum power of $80 \mathrm{~W}$ and a $12 \mathrm{~V}$ lead acid battery showed the efficiency of the proposed algorithm.

\section{REFERENCES}

[1] A. Luque and S. Hegedus, "Handbook of Photovoltaic Science and Engineering”, John Wiley \& Sons Ltd, 2003.

[2] A. Oi, "Design and Simulation of Photovoltaic Water Pumping System", Faculty of California Polytechnic State University, 2005.

[3] T.DenHerder, "Design and Simulation of Photovoltaic Super System Using Simulink", California Polytechnic State University, 2006.

[4] Nattorn Pongratananukul, "Analysis and Simulation Tools for Solar Array Power Systems", University of Central Florida, 2005.

[5] Lionel Vechiu, "Modélisation et Analyse de l'Intégration des Énergies Renouvelables dans un Réseau Autonome", Université du Havre, 2005.

[6] A.D. Halmsen et al, "Models for a Stand-Alone PV System", University of Denmark, 2000.

[7] Dezso Sera, Remus Teodorescu, "PV panel model based on datasheet values", Aalborg University, 2006.

[8] Amel Zenati, "Modélisation et simulation de microsystèmes multi domaines à signaux mixtes : vers le prototypage virtuel d'un microsystème autonome", Université Joseph Fourier Grenoble I, 2007.

[9] Robert W. Erickson, "Fundamentals of Power Electronics", Chapman \& Hall, 115 Fifth Avenue, New York, NY 10003, 1997.

[10] Robert Bausière, Francis Labrique, Guy Seguier, "Les Convertisseurs de l'Electronique de Puissance Volume 3
: La Conversion Continue -- Continue (2ème édition)", Paris : Lavoisier-Tec \& doc, 1997.

[11] Ned Mohan, Tore M. Undeland, William P. Robbins , "Power Electronics Converters, Applications And Design", John Wiley \& Sons, INC, 2003.

[12] W.Xiao, "A Modified Adaptative Hill Climbing Maximum Power Point Tracking (MPPT) Control Method For Photovoltaic Power Systems", The University of British Columbia, 2003.

[13] M.Angel Cid Pastor, "Conception et Réalisation de Modules Photovoltaïques Electroniques", Institut National des Sciences Appliquées de Toulouse, 2006.

[14] Todd Edward Persen, "FPGA-Based Design of a Maximum-Power-Point-Tracking System for Space Applications", University of Florida, 2004.

[15] V. Salas, E. Olias, A. Barrado, A. Lazaro, "Review of the maximum power point tracking algorithms for standalone photovoltaic systems", Solar Energy Materials \& Solar Cells 90 (2006) 1555-1578.

[16] Trishan Esram, Student Member, IEEE, and Patrick L. Chapman, Senior Member, IEEE, "Comparison of Photovoltaic Array Maximum Power Point Tracking Techniques", IEEE TRANSACTIONS ON ENERGY CONVERSION, 2006.

[17] D. Sera, T. Kerekes, R. Teodorescu, and F. Blaabjerg, "Improved MPPT method for rapidly changing environmental conditions", Aalborg University/Institute of Energy Technology, Aalborg, Denmark, 2006.

[18] Hannes Knopf, "Analysis, Simulation and Evaluation of Maximum Power Point Tracking (MPPT) Methods for a Solar Powered Vehicule", Portland State University, 1999.

[19] Bruno Burger, " Transformatorloses Schaltungskonzept für ein dreiphasiges Inselnetz mit Photovoltaikgenerator und Batteriespeicher ", Ph.D. dissertation, University of Karlsruhe, Karlsruhe, Germany, 1997.

[20] O. Boukli-Hacene, A. Chermitti, "Design of a library of components for autonomous photovoltaic system under Matlab/Simulink", The Eightth International Conference on Materials Sciences (CSM8) \& the Fifth International Conference of the Institute of Materials Systems (ISM5), Lebanon, 2012. 